DOI:10.5433/1984-7939.2017v2n1p97

\title{
ADAPTAÇÃo E UTILIZAÇÃo DE PORTEFÓlIO PARA APRENDIZAGEM REFLEXIVA E AUTÓNOMA NAS PRÁTICAS PEDAGÓGICAS DE INGLÊS
}

\author{
Miguel Afonso Vila ${ }^{1}$ \\ Ana Matos ${ }^{2}$
}

RESUMO: A Formação Inicial de Professores (FIP) tem sido marcada internacionalmente com a introdução de instrumentos de reflexão, que fazem parte das boas práticas de ensino e aprendizagem no âmbito das Ciências de Educação. Mas no contexto angolano esta inovação não é um facto. Assim, o presente artigo propõe adaptar e utilizar, na Prática Pedagógica do curso de Inglês, o Portfolio for Students Teachers of English no Instituto Superior de Ciências de Educação de Luanda (ISCED-POSTE). Para tal, utilizamos a metodologia quantitativa com recurso ao programa SPSS para determinar as frequências de preenchimento do portefólio e recorremos à metodologia qualitativa com realce à análise temática das entrevistas dos participantes. Da análise feita à sessão Self-Assessment, o Resource foi a categoria mais refletida com 38\%, enquanto o Independent learning com $6 \%$ foi a menos utilizada pelos estudantes. A categoria do Dossier mais expressiva é o Evidence From Lesson Observation and Evaluation (EFLOE) com 50\%. Tal como os participantes consideram que o ISCED-POSTE estimula a criatividade, promove a aprendizagem autónoma e reflexiva, contribui na organização do processo de aprendizagem e recomendam a sua utilização. Auguramo-nos que o presente trabalho sirva de protótipo para outros contextos de formação inicial de professores que privilegiam abordagens tradicionais de ensino nas práticas pedagógicas ou estágios.

PALAVRAS-CHAVE: Ensino de segunda lingua; Formação de professores; Reflexão; Autonomia; Práticas pedagógicas.

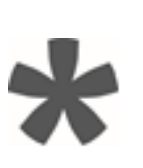

1 Doutorando pela Universidade Nova de Lisboa, Mestre em Ciências de Educação e Licenciado em Pedagogia pela Universidade Agostinho Neto. Docente do Instituto Superior Politécnico de Humanidade e Tecnologias do Huambo. Membro pesquisador do CETAPS (Centre for English, Translation, and Anglo-Portuguese Studies) da Faculdade de Ciências Sociais e Humanas da Universidade Nova de Lisboa. E-mail: anildovila@gmail.com

2 Docente do Departament of Modern Languages, Cultures and Literatures da Faculdade de Ciências Sociais e Humanas da Universidade Nova de Lisboa. Coordenadora de dois cursos de mestrado em Ensino de Inglês. Pesquisadora do Centre for English, Translation and Aglo-Portuguese Studies (CETEAPS) Email: anagoma2@gmail.com 
Vila e Matos

\title{
ADAPTATION AND USE OF PORTFOLIO FOR REFLEXIVE AND AUTONOMOUS LEARNING IN ENGLISH PEDAGOGICAL PRACTICES
}

\begin{abstract}
The Initial Teacher Training approaches have been characterized by the introduction of teaching tools that provide students with reflexive and autonomous learning capabilities. But this is not a fact in Angolan context. Therefore, this paper endeavours to adapt and use the Portfolio for Students Teachers of English in the Instituto Superior de Ciências da Educação de Luanda (ISCED-POSTE) in English course settings. For this purpose, we used a quantitative and a qualitative methodology, with emphasis on the thematic analysis used to assess the interviews. The analysis of the relative frequencies shows that, with 38\%, the Self-Assessment/Resource section was the category upon which respondents have most reflected. Accordingly, participants inferred that the ISCED-POSTE tool stimulates students' creativity, promotes reflexive and autonomous learning, and helps to organize learning process. Consequently, observed participants endorsed the use of the ISCED-POSTE in English course contexts. Hopefully, this research will be used as a model for other Initial Teacher Training contexts that are clinging to traditional approaches in their teaching and internship activities.
\end{abstract}

KEYWORDS: Second Language teaching; Teacher training; Reflection; Autonomy; Teaching practice.

\section{ADAPTACIÓN Y UTILIZACIÓN DE PORFOLIO PARA UN APRENDIZAJE REFLEXIVA Y AUTÓNOMA EN LAS PRÁCTICAS DE ENSEÑANZA DE INGLÉS}

RESUMEN: Los últimos años la Formación Inicial de Profesores (FIP) han sido revolucionados por la introducción de herramientas que suponen capacidades de reflexión y autonomía de los estudiantes para un aprendizaje eficiente. Sin embargo, eso no es una realidad en Angola. Luego, este articulo pretende contribuir a la solución de este problema con la presentación de los resultados de una investigación que adaptó y experimentó el uso del Portfolio for Students Teachers of English en el Instituto Superior de Ciências da Educação de Luanda/ISCED-POSTE. Se trata sustancialmente del hecho que, con 38\%, la sesión Self-Assessment/Resource es la categoría por la cual los estudiantes más se interesaron, con lo cual se entiende que ellos valoran positivamente el ISCEDPOSTE como herramienta de promoción de la creatividad, luego de aprendizaje reflexivo e autónomo de inglés. Metodológicamente, este resultado se obtuvo combinando un análisis cuantitativo de las cuestiones contenidas en el Portfolio con un análisis cualitativo de los discursos de las entrevistas a los estudiantes sobre las potencialidades del Portfolio en aportar capacidades de aprendizaje reflexivo y autónomo de inglés en el contexto de Angola. Deseamos que este trabajo funcione de prototipo para otros contextos de FIP que privilegian enfoques tradicionales en las prácticas de enseñanza.

PALABRAS-CLAVE: Enseñanza de segunda lengua; Formación de profesores; Reflexión; Autonomía; Prácticas de enseñanza. 


\section{Vila e Matos}

\section{Introdução}

O European Portfolio for Students Teachers of Language (EPOSTL) foi desenvolvido por uma equipa do Centro Europeu para as Línguas Modernas do Conselho da Europa, da qual fizeram parte professores formadores de diferentes países como: EUA, Austrália, Noruega, Polónia e Reino Unido (NEWBY et al., 2007). E surge na tentativa de harmonizar a formação inicial de professores na Europa.

Depois dos primeiros ensaios do EPOSTL em 2010, assiste-se atualmente a massificação deste portefólio, onde destacam-se as experiências da República do Vietname, da Albânia, da Turquia e do Japão. A implementação do ISCEDPOSTE teve como base a literatura de Newby et al. (2007), Jimbo et al. (2013), Nihlém (2011), Makinem (2011), Cakir e Balcikanli (2012) e Hoxha e Tafani (2015)

O presente artigo propõe-se adaptar e utilizar o Portfolio for Students Teachers of English do Instituto Superior de Ciências de Educação de Luanda (ISCED - POSTE), no curso de Formação de Professores de Inglês (FPI), como instrumento de reflexão crítica, contributo para os estudantes refletirem suas práticas pedagógicas. Para o prosseguimento da pesquisa colocamos a questão, o ISCED-POSTE se apresentará eficaz e inovador na aprendizagem reflexiva e autónoma das práticas pedagógicas de FIP do ISCED-Luanda? Esta experiência é um contributo prático para os contextos de FIP que privilegiam as abordagens tradicionais nos estágios de fim de curso.

\section{O European Portfolio For Student Teacher of Language (EPOSTL)}

O EPOSTL é um instrumento que pretende encorajar os estudantes que frequentam a Formação Inicial de Professores em Línguas (FIPL), a refletir sobre os conhecimentos e capacidades didáticas necessárias para ensinar. Este ajuda os estudantes a avaliar as suas próprias competências didáticas, monitorizar o seu progresso de aprendizagem e a registar as experiências de ensino durante a sua formação (NEWBY et al., 2007). Este portefólio é igual aos demais existentes e utilizados a nível de FIP, a diferença deste instrumento reside na amplitude da sua utilização e na flexibilidade para ser adaptado em diversos contextos de FIP, como é o caso das experiências Japonesa, Turca, Vietnamita e Albanesa. 


\section{Vila e Matos}

Apesar do EPOSTL ter sido concebido inicialmente para países da União Europeia, atualmente a sua utilização abrange países fora dela (NEWBY et al., 2007). O portefólio denominado Japanese Portfolio for Student Teachers of Languages (J-EPOSTL) foi adaptado do EPOSTL para o contexto de Formação de Professores de Língua Estrangeira (FPLE) no Japão (JIMBO et al., 2013).

Os objetivos do J-EPOSTL assemelham-se aos do EPOSTL, mas formulados em conformidade à realidade de formação de professores Japoneses: "O objetivo do J-POSTL é encorajar os estudantes a desenvolver as suas capacidades profissionais como professores de Língua Inglesa, registando sistematicamente o que aprendem na formação e durante os estágios"3 (JIMBO et al., 2013, p. 6). Entretanto, um estudo realizado pela Japan Association of College English Teachers (JACET), sobre a implementação do J-POSTL, gerou controvérsia sobre os resultados esperados. Alguns investigadores mostraram-se céticos sobre sua eficácia, alegando a diferença abismal entre o contexto de formação europeu e o Japonês, pondo em causa, por exemplo, o ambiente extraescolar, a interação professora aluno que é mais alargada no sistema europeu e a orientação didática do processo de ensino aprendizagem. Apesar da controvérsia, os resultados da sua implementação foram um sucesso (JACET, 2010, p. 302-303) ${ }^{4}$.

Por outro lado, pesquisadores da Gazi University, na Turquia, levaram a cabo um estudo piloto que visou implementar o EPOSTL como instrumento de (auto) reflexão e promotor de autonomia na aprendizagem no curso de formação inicial de professores de inglês (CAKIR; BALCIKANLI, 2012). O autores ao realizarem a referida pesquisa notaram que os participantes confirmaram que o EPOSTL é uma ferramenta que ajuda a moldar as capacidades e competências didáticas-linguísticas na formação inicial de professores. Tal como a maioria dos participantes concordaram que o EPOSTL melhora as competências de aprendizagem:

As seguintes afirmações demonstram a aprovação do EPOSTL pelos participantes: é uma grande oportunidade ter utilizado o EPOSTL porque ajudou-nos a perceber a nossa evolução nas práticas pedagógicas. $\mathrm{Eu}$ pude perceber as minhas

3 Nossa tradução: "The purpose of J-POSTL is to encourage student teachers to develop their professional competences as English language teachers by regularly recording what they have learned in their teacher training courses and during practice teaching"

${ }^{4}$ Ver documento completo em Japonês: http://www.waseda.jp/assoc-jacetenedu/2009_report_j.pdf 


\section{Vila e Matos}

potencialidades e fraquezas. Eu achei O EPOSTL realmente útil. Student Teacher A (CAKIR; BALCIKANLI, 2012, p. 9) ${ }^{5}$

Finalmente, na República da Albânia, Hoxha e Tafani (2015) fizeram um estudo sobre a utilização do EPOSTL como instrumento de reflexão nos estágios do curso de Formação Inicial de Professores de Línguas no Aleksander Xhuvani University, na cidade de Elbasan, na Albânia. Inicialmente a utilização do EPOSTL foi dificil para os estudantes, porque 90\% dos 38 participantes na investigação nunca tinha utilizado algum portefólio. Segundo as autoras, depois dos estudantes terem compreendido como se preenche o portefólio, o número dos descritores preenchidos por semana aumentara significativamente; e no final os participantes concluíram:

Quando utilizas o EPOSTL possibilita-te controlar tudo, porque ele ajuda e prepara-te em todos os sentidos. O EPOSTL é uma boa ferramenta para manter o controle das suas próprias capacidades, ajuda a perceber o quanto tens evoluído durante um periodo de tempo, comparado ao início da formação. ${ }^{6}$ (HOXHA; TAFANI, 2015, p. 76).

\section{Relato empírico da investigação}

Considerando as múltiplas experiências, construimos um portefólio no Instituto Superior de Ciências de Educação de Luanda e que denominamos, Portfolio for Students Teacher's of English (ISCED-POSTE). É um instrumento de reflexão desenvolvido no âmbito da pesquisa sobre FIP no Instituto Superior de Ciências de Educação de Luanda (ISCED-Luanda) em Angola. Este portefólio é uma construção adaptada do European Portfolio for Student Teachers of Languages - EPOSTL e possui características próprias em conformidade ao contexto de Angola. O processo de adaptação que explicitaremos adiante considerou documentos de base das práticas pedagógicas de formação inicial de professores de inglês no ISCED-Luanda e teve como objetivo preencher lacunas verificadas nas práticas pedagógicas daquele curso.

${ }^{5}$ Nossa tradução: The statements like the following showed their approval of the use of the EPOSTL. It is a chance that we used EPOSTL because it showed us our development in teaching. I managed to see my mistakes as well as strengths. I really found it useful.

${ }^{6}$ Nossa tradução: When you use EPOSTL you can have everything under control because it helps and prepares you in everything. EPOSTL is a good way to keep track of your own skills, meaning how much you have advanced during a period of time compared to the previous time you used EPOSTL. 


\section{Vila e Matos}

\subsection{Estrutura do portefólio}

O ISCED - POSTE contém quatro partes. Inicialmente apresenta uma breve introdução, onde se destaca a razão da construção do portefólio e explicita o processo da adaptação. A primeira parte do portefólio, denominado Personal Statement Section, ajuda o estudante a refletir sobre aspetos relacionados com o ensino de modo geral e incentiva-lhe a refletir questões importantes no início da sua formação (NEWBY et al., 2007). A segunda, designada Self Assessment Section, relaciona-se com as politicas que influenciam os currículos, programas educacionais que os estudantes devem considerar como elementos-chave para aprendizagem. A composição desta parte do portefólio é definida por vários descritores selecionados com base aos programas de FIPI do ISCED-Luanda. A terceira parte denominada Dossier tem a função de ajudar os estudantes a organizar o seu próprio processo de aprendizagem, sua autoavaliação e certificar que os descritores preenchidos na parte anterior do portefólio traduzem-se em competências adquiridas pelos estudantes. O Dossier coleciona todas as evidências das aulas observadas, lecionadas, planificadas, reflexões escritas feitas pelos estudantes, supervisores e outros intervenientes na formação (NEWBY et al., 2007). Finalmente, a quarta parte, Final Report, tem como função flexibilizar o ISCED-POSTE, permite o estudante fazer anotações espontâneas fora de descritores previamente definidos.

\subsection{Fases do processo de construção do ISCED-POSTE}

A construção do portefólio obedeceu fases conforme descritas abaixo:

Identificar - tivemos contato com os documentos europeus, nomeadamente o Commom European Framework Reference (CEFR), o site da $\mathrm{ECML}^{7}$, o EPOSTL ${ }^{8}$, o ELP ${ }^{9}$. Analisamos o guião que compila diferentes pesquisas sobre a utilização ${ }^{10}$ do EPOSTL e outros documentos relacionados com politicas linguísticas europeias. Esta fase teve como objetivo perceber as politicas FIP que regulam o contexto europeu e encontrar as melhores estratégias de implementar o ISCED-POSTE no contexto de formação inicial em Angola.

\footnotetext{
${ }^{7}$ European Centre for Modern Languages of the Council of Europe: http://www.ecml.at/

${ }^{8}$ Site do EPOSTL: http://elp.ecml.at/

${ }^{9}$ European Language Portfolio: http://www.coe.int/t/dg4/education/elp/

${ }^{10} \mathrm{http}: / /$ www.ecml.at/Resources/ECMLPublications/tabid/277/language/en-GB/Default.aspx
} 


\section{Vila e Matos}

Familiarizar - concentrámo-nos em ler os documentos ${ }^{11}$ que regulam a formação inicial de professores de inglês no ISCED-Luanda, para verificar a disparidade e convergência entre ISCED-POSTE e o EPOSTL. Nesta fase, procurámos a opinião de alguns professores sobre o processo da implementação do ISCED-POSTE, tendo alguns sugerido a reorganização dos descritores por ordem de conteúdos e outros sugeriram a incorporação dos elementos técnicoslinguísticos. Entretanto, verificámos os aspetos do EPOSTL que interessavam os objetivos da implementação do ISCED-POSTE e por conseguinte: eliminamos os descritores incompativeis ao contexto de formação em Angola; os descritores que refletem a formação contínua de professores; os descritores que são especificamente dirigidos para o contexto europeu e aqueles que não se ajustam aos principais objetivos da prática pedagógica do ISCED-Luanda. Exemplo:

Eu compreendo os principios formulados nos principais documentos Europeus (Ex. Quadro Comum Europeu de Referência; Perfil Europeu de Linguas). (EPOSTL, p.15)

Retificamos todos os descritores que não são claros na sua definição, e aqueles gerais quando se refere a língua em causa/alvo, utilizando por exemplo: "target language"; foram alterados substituindo a expressão lingua alvo por "Inglês". Exemplo:

Eu posso utilizar várias estratégias quando os estudantes não compreendem a lingua algo.

Eu posso encorajar os estudantes a conectar a lingua alvo com as outras linguas que eles falam ou tenham aprendido, sempre que for necessário. (EPOSTL, p. 43)

Acrescentamos alguns descritores ligados ao contexto específico de formação inicial de professores em Angola e os que refletem os objetivos gerais das práticas pedagógicas no ISCED-Luanda. Exemplo:

\section{Eu posso selecionar mapas e cartazes adequados para aprendizagem dos estudantes. (Acrescentado) \\ Eu posso orientar os estudantes a utilizarem os novos manuais publicados pela Reforma Educativa. (Acrescentado) (ISCED- POSTE. p. 11-13)}

Terminada esta fase, o instrumento foi entregue a um docente experiente daquela instituição, para verificar e opinar sobre as competências relacionadas ao contexto de formação do ISCED-Luanda. Devolveu-nos o instrumento depois

${ }^{11}$ Analisamos o programa geral de práticas pedagógicas; o guia de observação de aula dos estudantes; o guia de elaboração do portfólio de práticas pedagógicas e as fichas de observação. 


\section{Vila e Matos}

de ter opinado sobre a implementação. Avaliámos as retificações e seguimos as orientações que se afiguravam pertinentes e necessárias para a implementar o portefólio.

\section{Metodologia e Procedimentos}

A pesquisa ocorreu no Instituto Superior de Ciências de Educação de Luanda, trabalhamos com a Repartição de Inglês no Departamento de Letras Modernas e teve início em Junho e terminou em Dezembro de 2016, o que corresponde um semestre letivo no ensino superior em Angola. Selecionamos dois professores considerando o tempo de serviço e a disponibilidade em participar na pesquisa como critérios de inclusão. Selecionamos também 40 estudantes $^{12}$ do $4^{\circ}$ ano do curso de Inglês, totalizando 42 participantes. O objetivo da investigação é adaptar e utilizar o Portfolio for Students Teachers of English do Instituto Superior de Ciências de Educação de Luanda (ISCED POSTE), no curso de formação de professores de Inglês como instrumento de reflexão crítica, contributo para os estudantes refletirem suas práticas pedagógicas. Para o alcance do mesmo, colocamos a questão: o ISCED-POSTE se apresentará eficaz e inovador na aprendizagem reflexiva e autónoma das práticas pedagógicas?

Porém, atualmente a discussão sobre metodologias quantitativa e qualitativa radica-se numa posição de hierarquização. Neste sentido, corroboramos com Gonçalves (2010, p. 42) ao defender que "os processos educativos só beneficiarão com uso de metodologias diversas e de abordagens multi, inter e transdisciplinares." Neste âmbito, considerando a natureza da pesquisa, recorremos às metodologias qualitativas para analisar as entrevistas, e empregamos a metodologia quantitativa para analisar as frequências relativas e absolutas de preenchimento do portefólio. Para melhor compreendermos o impacto da utilização do portefólio e seu contributo nas práticas pedagógicas, recorremos a entrevistas semiestruturadas aplicadas aos estudantes no final do programa. O objetivo das entrevistas consistiu em recolher informação para avaliar a prestação do ISCED-POSTE. Deste modo, as perguntas formuladas nas entrevistas representaram os objetivos da pesquisa e constituíram por si só as

\footnotetext{
12 População é composta por 85 estudantes do $3^{\circ}$ e $4^{\circ}$ anos regular que realizam práticas pedagógicas. Selecionamos $47 \%$ dos estudantes que fazem parte do $4^{\circ}$ ano; escolhemos o $4^{\circ}$ ano porque as práticas são mais sistemáticas do que na outra turma.
} 


\section{Vila e Matos}

categorias da análise temática, produzindo por sua vez características/indicadores que responderam os temas propostos (BARDIN, 2011). Entretanto, para implementar o portefólio seguimos o caminho conforme explicitamos abaixo.

\subsection{Procedimentos para implementar o ISCED-POSTE}

Adaptar - com objetivo de tornar o projeto inclusivo, fornecemos algumas cópias do ISCED - POSTE aos professores participantes na investigação, para terem ideia do que pretendiamos desenvolver naquele curso. Antecipamos a entrega do material aos professores, para que eles pudessem também avaliar e discutir connosco a seleção de descritores para o portefólio. Os professores participantes tiveram um papel relevante na escolha e acréscimo de descritores; depois de termos chegado a um consenso sobre a composição do portefólio, seguiu-se a apresentação.

Apresentar - o ISCED-POSTE foi apresentado aos estudantes através de três workshops sistemáticos e várias exposições de slides.

Distribuir e formar - depois de analisarmos a possibilidade de trabalhar com portefólio virtual, concluímos que não havia condições para utilizar o ISCED-POSTE online pelas seguintes razões: a) falta de internet regular e com uma velocidade aceitável; b) a falta de um espaço de computadores na instituição onde os estudantes possam aceder gratuitamente; c) a inaptidão de alguns estudantes para manusear internet, entre outras, contribuíram na decisão de entregar as cópias físicas do ISCED-POSTE aos participantes. Depois da entrega do portefólio, explicamos as quatro seções que o compõem nomeadamente: Personal Statement Section, Self-Assessement Section, Dossier e o Final Report. Pacientemente fomos explicando o preenchimento com exemplos práticos. Escolhemos sempre os descritores de fácil compreensão. Por exemplo, o descritor número um da Self Assessment Section, na categoria Conduct a Lesson, subcategoria A) Using Lesson plans (ISCED-POSTE, p. 13):

\section{- I can start a lesson in an engaging way}

Colocamos este descritor no quadro e explicamos em que seção, categoria e subcategoria pertencia. Demonstramos também como é que esta afirmação que chamamos tecnicamente de descritor é uma competência que pode ser adquirida 


\section{Vila e Matos}

pelos estudantes durante as práticas pedagógicas. Explicamos o que significa start a lesson in an engaging way. Dissemos aos estudantes que em detalhe isto quer dizer, por exemplo:

- Começar a aula com uma conversa relacionada com vida académica ou familiar dos estudantes;

- Começar a aula com uma música áudio ou visual para relaxar o ambiente e preparar os estudantes para a nova aula, etc.

Exemplificamos no quadro como deveria ser preenchido:

- I can start a lesson in an engaging way (Sou capaz de iniciar a aula de modo ativo)

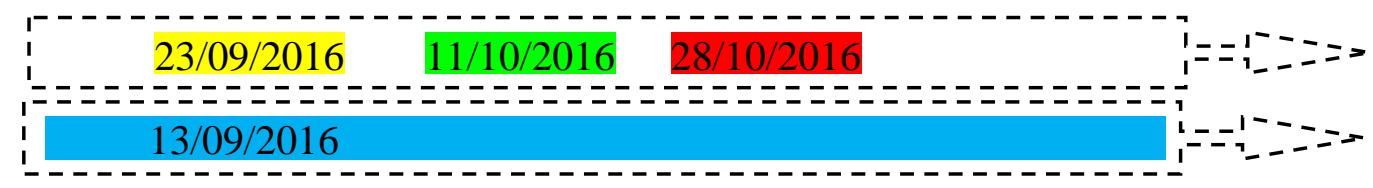

No primeiro caso (seta), o estudante tem três datas que ele considera ter adquirido a competência do descritor em referência. Na primeira data, através da aula que ele ministrou, considerou ter realizado uma atividade que reflete a competência (começou a aula com uma canção relacionada com o conteúdo a ensinar). Mesmo assim, este estudante ainda não se considera perito em começar a aula de modo ativo por várias razões. Seguem-se as duas datas que também considera ter realizado atividades que refletem esta competência. Já no segundo exemplo (seta), o estudante leciona uma aula e entende que tem perícia ou domínio daquela competência, por esta razão ele pintou a seta toda, o que significa domínio significativo desta competência. Portanto, o nível da pintura da seta significa nivel de competência adquirida, ou seja, quanto mais pintada for a seta, mais competência adquiriu naquele descritor e vice-versa. Posteriormente, demonstramos com exemplos práticos o preenchimento do dossier. Abaixo a figura de correspondência entre os descritores preenchidos e a evidência que sustenta a competência alegadamente adquirida:

I can start a lesson in an engaging way (Sou capaz de iniciar a aula de

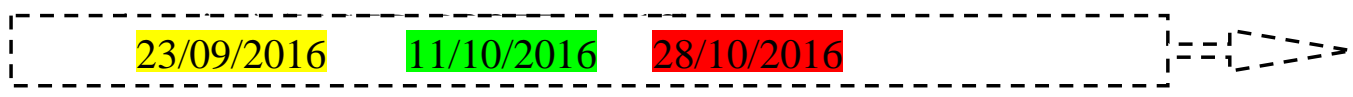


Reflection grid (Grelha de reflexão) (Dossier-Section) (Seção de evidências)

\begin{tabular}{|c|c|c|}
\hline $\begin{array}{l}\text { Descriptor number (s) } \\
\text { (Número de descritor) }\end{array}$ & $\begin{array}{l}\text { Date of } \\
\text { reflection } \\
\text { (data da } \\
\text { reflexão) }\end{array}$ & $\begin{array}{l}\text { Your comments } \\
\text { (Comentários) }\end{array}$ \\
\hline $\begin{array}{l}\text { Conducting a Lesson } \\
\text { A1 } \\
\text { (Ministrando a aula) }\end{array}$ & $23 / 09 / 2016$ & $\begin{array}{l}\text { Unit } 1, \text { where given a basic } \\
\text { information on how to start e lesson. } \\
\text { (Unidade 1, aprendemos como } \\
\text { começar uma aula.) }\end{array}$ \\
\hline $\begin{array}{l}\text { Conducting a Lesson } \\
\text { A1 } \\
\text { (Ministrando a aula) }\end{array}$ & $11 / 10 / 2016$ & $\begin{array}{l}\text { My } 1 \text { st teaching practice "expressing } \\
\text { the future". I was fear on my } \\
\text { starting, but I did it. (Na minha } \\
\text { primeira aula prática, fiquei com } \\
\text { medo no início mas consegui } \\
\text { ministrá-la.) }\end{array}$ \\
\hline $\begin{array}{l}\text { Conducting a Lesson } \\
\text { A1 } \\
\text { (Ministrando a aula) }\end{array}$ & $28 / 10 / 2016$ & $\begin{array}{l}\text { My colleagues observed my lesson } \\
\text { and wrote to their observation that I } \\
\text { started the lesson in an engaging } \\
\text { way. } \\
\text { (Os meus colegas observaram a } \\
\text { minha aula e escreveram nas suas } \\
\text { respectivas grelhas de observação } \\
\text { que comecei a aula de modo ativo.) }\end{array}$ \\
\hline
\end{tabular}

Nesta seção, Conducting a Lesson (ministrando a aula), representa a categoria preenchida. A letra A representa a subcategoria Using a Lesson Plan (utilizando o plano de aula), enquanto o número 1 representa o número do descritor preenchido e a data da realização da atividade. No item comentários, o estudante explica como adquiriu as competências mencionadas nos descritores. As datas que aparecem nos descritores são as mesmas que figuram no dossier, porque trata-se da mesma atividade refletida.

Dossier (Evidências):

List of documents (Lista de evidências) 
Vila e Matos

\begin{tabular}{|c|c|c|c|c|}
\hline $\begin{array}{l}\text { Doc. } \mathbf{N}^{\circ} \\
\left(\mathrm{N}^{\circ} \mathrm{de}\right. \\
\text { doc. })\end{array}$ & $\begin{array}{l}\text { Date } \\
\text { (Data) }\end{array}$ & $\begin{array}{l}\text { Category } \\
\text { (Categoria) }\end{array}$ & $\begin{array}{c}\text { Description } \\
\text { (Descrição da } \\
\text { evidência ) }\end{array}$ & $\begin{array}{c}\text { Comments } \\
\text { (Comentários reflexivos) }\end{array}$ \\
\hline 1 & $11 / 10 / 2016$ & $\begin{array}{l}\text { Conductinga } \\
\text { Lesson A1 } \\
\text { (Ministrando } \\
\text { a aula) }\end{array}$ & $\begin{array}{l}\text { The evidence } \\
\text { is the Lesson } \\
\text { Plan } \\
\text { (A evidência é } \\
\text { o meu plano } \\
\text { de aula ) }\end{array}$ & $\begin{array}{l}\text { I never been in front of } \\
\text { student and this was my first } \\
\text { time. It was very difficult for } \\
\text { me, I really selected the } \\
\text { conversation that I could } \\
\text { have with students, but } \\
\text { didn't happen as I planned. } \\
\text { Even though, I was able to } \\
\text { talk and prepare them for } \\
\text { new lesson. (Foi a primeira } \\
\text { vez que estive em frente de } \\
\text { estudantes. Foi dificil para } \\
\text { mim porque selecionei uma } \\
\text { conversa que teria com os } \\
\text { estudantes, infelizmente não } \\
\text { correu como tinha planeado. } \\
\text { Apesar de tudo, fui capaz de } \\
\text { prepará-los para a nova } \\
\text { aula.) }\end{array}$ \\
\hline 2 & $28 / 10 / 2016$ & $\begin{array}{l}\text { Conducting a } \\
\text { Lesson A1 } \\
\text { (Ministrando } \\
\text { a aula) }\end{array}$ & $\begin{array}{l}\text { My } \\
\text { colleagues } \\
\text { observation } \\
\text { sheet } \\
\text { (Grelhas de } \\
\text { observação } \\
\text { dos meus } \\
\text { colegas) }\end{array}$ & $\begin{array}{l}\text { Some of my colleagues wrote } \\
\text { in their observation that I } \\
\text { started the lesson in an } \\
\text { engaging way. On this stage } \\
\text { of lesson, I select a well- } \\
\text { known music by students } \\
\text { and this music was related } \\
\text { with the lesson. It's served to } \\
\text { prepare student for new } \\
\text { lesson. (Muitos dos meus } \\
\text { colegas escreveram nas suas } \\
\text { grelhas de observação, que } \\
\text { cmecei a aula de modo ativo. } \\
\text { Nesta fase da aula selecionei } \\
\text { uma música bem conhecida } \\
\text { pelos estudantes e estava } \\
\text { relacionada com a aula à } \\
\text { ministrar.) }\end{array}$ \\
\hline
\end{tabular}

Ilustração 1 Demonstração da utilização do ISCED-POSTE. Elaboração do autor, adaptado do EPOSTL. 


\section{Vila e Matos}

O primeiro caso reportado integra várias datas de reflexão (três reflexões), enquanto o caso que se segue circunscreve-se em uma única reflexão efeituada pelo estudante:

I can start a lesson in an angaging way (Sou capaz de iniciar a aula de

Reflection grid (Grelha de reflexão) (Dossier-Section) (Seção de evidências)

\begin{tabular}{|l|l|l|}
\hline $\begin{array}{c}\text { Descriptor number } \\
\text { (s) }\end{array}$ & $\begin{array}{c}\text { Date of } \\
\text { (Númeflection de descritor) } \\
\text { (Data de } \\
\text { reflexão) }\end{array}$ & \multicolumn{1}{c|}{$\begin{array}{c}\text { Your comments } \\
\text { (Comentários) }\end{array}$} \\
\hline $\begin{array}{l}\text { Conducting a Lesson } \\
\text { A1 }\end{array}$ & $13 / 09 / 2016$ & $\begin{array}{l}\text { All my colleagues was unanimous that I } \\
\text { started my lesson in excellent way. I am } \\
\text { already a teacher in public school and I } \\
\text { do it every days on my lessons. (Meus } \\
\text { colegas foram unânimos em dizer que } \\
\text { comecei a aula de modo ativo. Eu já sou } \\
\text { professor na escola pública e faço isto } \\
\text { todos os dias.) }\end{array}$ \\
\hline
\end{tabular}

Ilustração 2 Demonstração da utilização prática do ISCED-POSTE. Caso B, elaboração do autor.

Utilizar - nesta fase da pesquisa concentramo-nos em monitorizar a utilização do portefólio pelos estudantes; esclarecer as dificuldades encontradas ao utilizar o portefólio e encorajá-los a registarem sistematicamente as experiências das práticas pedagógicas (MAKINEM, 2011). Exortamos os estudantes a compilar evidências tais como: plano de aula, exemplo de uma tarefa orientada pelo professor, as avaliações e observações escritas feitas por colegas e por supervisores e outros documentos de reflexão que fazem parte das práticas pedagógicas (NIHLÉN, 2011). Depois das práticas, os estudantes e o pesquisador tinham 40 minutos para refletir e preencher novos descritores na seção Self-Assessment Section (seção da autoavaliação). Durante estas sessões orientávamos os estudantes a juntarem-se em pequenos grupos para discutir 


\section{Vila e Matos}

sobre as suas respetivas evidências. Para além de preencherem novos descritores na sala de aula, foram sistematicamente exortados a continuar o preenchimento fora da sala de aulas.

Na semana a seguir às aulas práticas, o pesquisador supervisionava as ações (descritores preenchidos fora da sala) da semana anterior às práticas. Esta supervisão era feita através da receção dos portefólios dos estudantes. Enquanto os estudantes assistiam às aulas normais, o pesquisador na biblioteca analisava os descritores preenchidos. Caso houvesse muito erro de preenchimento, marcávamos para o dia seguinte uma sessão extraordinária de 15 a 30 minutos para corrigir as falhas e dissipar possiveis dúvidas que surgiram ao longo da semana. Este procedimento repetiu-se até ao final do programa das práticas pedagógicas.

\section{Análise e discussão dos resultados}

4.1.Análise de Frequências de preenchimento de descritores

Gráfico 1- Análise das categorias do self-assessment

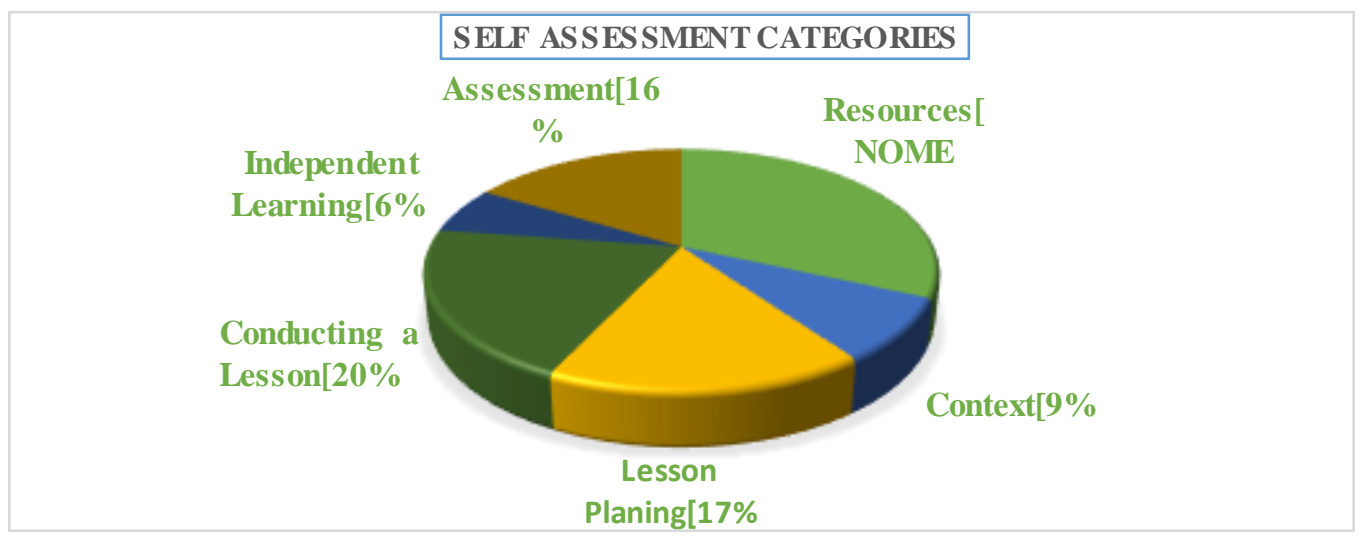

Fonte: Elaboração do autor

As categorias menos refletidas são: Independent Learning (aprendizagem autónoma), Context (Contexto) e Assessment (Avaliação), representados por 6\%, $9 \%$ e $16 \%$ respetivamente. Ao analisarmos os portefólios e as respetivas evidências que sustentam cada descritor refletido, notamos que havia poucas evidências desta categoria, principalmente nas subcategorias Evaluation (avaliação) e Designing Assessment Tools (produção de ferramentas de avaliação). Estas duas subcategorias apresentaram baixas evidências e consequentemente a categoria em geral se expressou 103 vezes representando a média mais baixa de 


\section{Vila e Matos}

toda seção Self Assessment (autoavaliação). Entendemos que uma das principais razões desta baixa média de preenchimento é o facto desta categoria por si só apresentar-se como categoria que exige reflexão. Ora, se os estudantes não puderam apresentar evidências que sustentassem esta categoria, pensamos que é natural a baixa registada, por outro lado, o tipo de abordagem tradicional que se privilegia no ISCED-Luanda em detrimento de aprendizagem reflexiva e autónoma, pode explicar também a baixa média desta categoria.

Das categorias mais preenchidas, destacamos a Resources (Recursos didáticos) com 520 preenchimentos, que corresponde cerca de 32\%. Conducting a Lesson (Ministrando a aula) com 332 vezes preenchida, alcançando 20\%, enquanto a categoria Lesson Planing (Planificação) aduz-se em terceiro lugar com $17 \%$, sendo refletida 279 vezes. Porém, segundo as evidências analisadas, notouse que a principal evidência que sustentou as três primeiras categorias foram os planos de aulas e as grelhas de observação que os estudantes utilizam durante as práticas pedagógicas. Analisamos o modelo de plano de aula utilizado no ISCED-Luanda, percebemos que existe naquele modelo a obrigatoriedade dos estudantes introduzirem os recursos utilizados para a ministração das práticas pedagógicas, sem os quais a aula é fortemente criticada pelo professor e pelos estudantes. Este facto fez aumentar significativamente o preenchimento da categoria Resources (recursos didáticos). Mas constatamos que, os descritores que dizem respeito às TICs na categoria Resources, quase todos eles não foram refletidos. Mais da metade dos portefólios deixou aqueles descritores em branco. O que nos levou a concluir que as TICs nas práticas pedagógicas do curso de formação inicial de professores no ISCED-Luanda, ainda não é uma realidade. Esta tendência ficou também confirmada nos planos de aulas que não mencionavam recursos ligados às TICs. Entendemos ainda que a ausência da utilização das TICs pode confirmar a tendência tradicionalista de ensino vincada naquela instituição. 
Vila e Matos

\subsection{Análise das evidências compiladas por categorias}

Gráfico 2- Análise das categorias da sessão Dossier

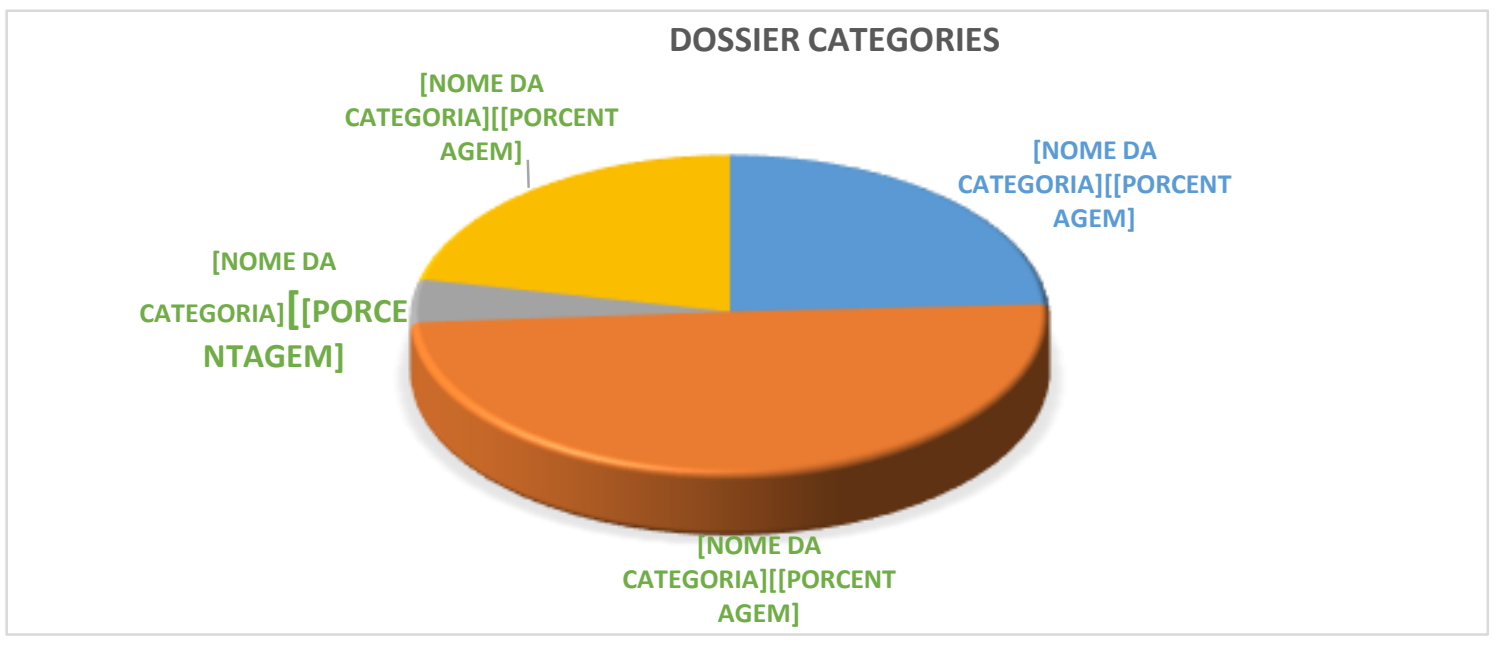

Fonte: Elaboração do autor

A categoria mais expressiva, segundo o gráfico, é a Evidence From Lesson Observation And Evaluation (ELOE) (Evidências das aulas observadas e avaliadas) que apresentou 215 evidências, representando a metade das evidências do dossier com 50\%. Com 105 evidências ficou a categoria Evidence From Lesson you Have Given (EFLHG) (Evidências das aulas ministradas), representando um total de $24 \%$. E em último lugar, com 19 evidências 4\%, ficou a categoria que envolve as evidências dos demais atores que participam indiretamente no processo das práticas pedagógicas dos estudantes.

Analisadas as categorias do dossier, concluímos que é natural que a categoria Evidence From Lesson Observation And Evaluation (Evidências das aulas observadas e avaliadas) liderasse o número de evidências utilizadas para reflexão. Porque as práticas pedagógicas do ISCED-Luanda envolvem uma componente em que os estudantes fazem uma avaliação/análise escrita da aula prática do colega. No entanto, se um estudante ministrar uma aula prática e na mesma estiverem presentes 30 colegas seus, no final o estudante que lecionou a aula terá em sua posse 30 avaliações escritas, vindas dos seus colegas. Esta natureza de evidência faz parte do Evidence from Lesson Observation and Evaluation (evidências das aulas observadas e avaliadas). Entretanto, sempre que um estudante ministrasse uma aula, o procedimento era o mesmo para todos. $\mathrm{E}$ estas avaliações dos colegas foram anexadas nos seus respetivos portefólios. A 


\section{Vila e Matos}

categoria Evidence From Lesson you Have Given (evidências das aulas ministradas) aparece em segundo lugar e apresentou com maior frequência, evidências relacionadas com os planos de aulas, embora tenhamos constatado algumas evidências relacionadas com os conteúdos e atividades realizadas na aula, a diferença com os planos de aula foi significativa. Porém, a diferença do EFLHG com a categoria do Evidence From Reflection (ER) (Evidências de reflexões feitas) não é estaticamente significativa, se considerarmos as percentagens representadas no gráfico. O ER aparece com 22\%, enquanto o EFLHG representa $24 \%$ do total das evidências. Porém, acreditamos que a perspetiva reflexiva do ISCED-POSTE, encorajou a produção deste tipo de evidências.

\subsection{As vozes dos atores: análise das entrevistas}

As entrevistas aplicadas aos estudantes tiveram o objetivo avaliar a prestação do portefólio nas práticas pedagógica. Para tal, analisamos os seguintes temas:

\subsubsection{ISCED-POSTE instrumento de reflexão}

Sobre reflexão, McGrego (2011) afirma que o desenvolvimento profissional na prática reflexiva é uma das atividades fundamentais e torna-se mais importante quando sustenta o desenvolvimento dos estudantes em formação inicial. Para autora, as práticas reflexivas têm lugar quando o professor se depara inesperadamente com situações que o obrigam a parar e autoquestionarse, de como terá sucedido a inesperada situação, e nesse sentido questiona-se repetidas vezes: O que foi? Quando foi? Como foi? Estas questões podem ser irrelevantes no princípio da reflexão, mas elas tornam-se gradualmente mais significativas ao longo do tempo. Entretanto, os indicadores temáticos apresentados pelos participantes mostram características da ação reflexiva, como lemos:

[...] durante o preenchimento do ISCED-POSTE vi-me obrigado a questionar-se com base nos descritores do ISCED-POSTE, [...] por exemplo no Conducting a Lesson, questionei-me se no decorrer das minhas aulas práticas soube gerir o tempo? Soube terminar a aula no tempo estipulado? Ajudou-me bastante, [...] (Estudante-A, 2016) 


\section{Vila e Matos}

Afigura-se pertinente considerar o facto do ISCED-POSTE ter levado o participante a questionar a sua própria atuação, como afirmou McGrego (2011), os questionamentos podem parecer irrelevantes no princípio, mas na medida em que o estudante vai exercendo sistematicamente a função de professor, estes questionamentos ganham importância para o alcance dos objetivos previamente propostos. Neste âmbito, o Estudante-R (2016) afirma que, quando se deparou com ISCED-POSTE encontrou várias questões das quais ele sabia ou já tivera aprendido, mas que não fazia o uso destas competências nas suas atividades. Segundo o mesmo participante, "O ISCED-POSTE ajudou-me a olhar mais além nesta perspetiva e entender melhor, é algo que praticamente diria que estava quase distraido [...]' (Estudante-R, 2016). Ora, o ato de refletir na declaração deste participante, está no facto de meditar profundamente no processo da prática pedagógica e ter percebido por si só que despertou competências didáticas ao afirmar que estava quase distraído. O outro participante declarou:

[...] ajudou-me muito e eu creio que [...] as próximas vezes, se eu tiver a chance de usá-las nas próximas vezes, [...] eu irei preencher de melhor maneira e outra coisa a partir do ano que estamos a suceder, as aulas serão mais críticas da minha parte [...]. (Estudante-F, 2016)

O Estudante-F (2016) ao utilizar o ISCED-POSTE foi levado a refletir sobre o seu modo de atuação e, consequentemente, tomou decisões novas para melhorar a sua atuação docente afirmando que nos próximos tempos, as aulas seriam mais reflexivas. Neste sentido de competência reflexiva, Richards (1991) confirma que ser professor reflexivo exige do mesmo a consciência das ações e respetivas consequências, o que pressupõe ir além das atividades reflexivas realizadas pelos professores. Por outro lado, Eraut (2000 apud CARTWRIGHT, 2011) referindo-se a diz que a prática reflexiva é o conhecimento tático do professor. Para este autor, quando planificamos e questionamos simultaneamente, procuramos de forma consciente mecanismos que facilitam o alcance dos objetivos propostos. Nesta perspetiva, os participantes disseram que o ISCED-POSTE:

[...] nos mantêm sempre em contacto com o que hei de ensinar, nos mantem também em contacto com os métodos que vamos usar ao ensinar, também as necessidades dos nossos alunos, bem como o 


\section{Vila e Matos}

que nós precisamos fazer para atingir os nossos objetivos quando nós planificamos as nossas aulas. (Estudante-V, 2016)

\subsubsection{ISCED-POSTE promotor de aprendizagem autónoma}

Para Cakir e Balcikanli (2012, p.3), a autonomia educacional é posicionar o estudante no centro da aprendizagem, concedendo-lhe liberdade para transformar as experiências aprendidas em novos saberes. Segundo aqueles autores, o estudante é considerado protagonista da aprendizagem. Neste âmbito, os participantes produziram os seguintes indicadores temáticos, "[...] levou-me a uma introspeção e ajudou-me a utilizar algumas técnicas para avaliar os meus alunos numa aula" (Estudante-A, 2016). O que achamos pertinente, é o facto de o participante utilizar técnicas diferenciadas que o ajudaram a avaliar os seus alunos. Embora ele não especifica que técnicas usou, mas transparenta existir independência na iniciativa do estudante. Enquanto que outro participante afirma que durante a utilização do portefólio foi levado a rever o que não se lembrava, isto entende-se como ação autónoma, "[...] durante o preenchimento fez-me rebuscar alguns conteúdos que eu já tinha esquecido." (Estudante-A1, 2016).

De acordo o Estudante-F (2016), "o outro aspeto que me marcou foi a questão que retrata da autonomia dos alunos, eu realmente não sabia e marcoume bastante, porque aprendi que posso ajudar o estudante aprender por si só." Este participante denota explicitamente que, de modo autónomo aprendeu que pode servir apenas de facilitador do processo de ensino e aprendizagem enquanto professor. Esta característica indica como aquele portefólio pode ajudar os estudantes a aprenderem de modo autónomo, tal como é defendida por Cakir e Balcikanli (2012, p.3), aprendizagem autónoma deve tornar o estudante protagonista da sua própria aprendizagem. O Estudante-R (2016) postulou que "[...] até que haviam algumas competências que durante uma aula que eu tive, não fazia noção. Mas ao vê-la descrito no ISCED-POSTE, eu pude perceber que eu desenvolvi aquela competência." Os indicadores da aprendizagem autónoma nesta declaração prendem-se no facto do participante ser levado a razão e tomar consciência da sua própria aprendizagem na ausência do seu professor. Por 


\section{Vila e Matos}

outro lado, o indicador temático apresenta o participante como protagonista da sua própria aprendizagem; diriamos que, o estudante descobre a sua própria competência pedagógica de modo autónomo.

4.3.3 ISCED-POSTE comparado com a grelha de reflexão do ISCEDLuanda

Ao questionarmos os participantes sobre a possivel comparação do ISCEDPOSTE com a grelha de reflexão que eles utilizam para as práticas pedagógicas no ISCED-Luanda, nosso foco é perceber qual dos dois instrumentos serve melhor as práticas pedagógicas dos estudantes. Pedimos também aos estudantes que justificassem a sua escolha/resposta. Na sequência, os participantes produziram os seguintes indicadores temáticos, como resumido na seguinte tabela: 


\section{Vila e Matos}

Tabela 1- Comparação do ISCED-POSTE com a grelha de reflexão das práticas pedagógicas do ISCED-Luanda.

\begin{tabular}{|c|c|c|c|}
\hline Participante & $\begin{array}{l}\text { Qual dos dois portefólios preferes utilizar } \\
\text { nas PP? } \\
\text { (Indicador temático) }\end{array}$ & $\begin{array}{c}\text { Por quê? } \\
\text { (Justificativa da escolha) }\end{array}$ & Por que razão excluiu outro portefólio? \\
\hline Estudante-A & $\begin{array}{l}\text { "[...] para ser sincero e honesto, eu prefiro } \\
\text { o ISCED-POSTE." }\end{array}$ & $\begin{array}{l}\text { "[...] porque ajudou-me a refletir as minhas aulas práticas, } \\
\text { através deste, pude superar algumas falhas e desenvolver } \\
\text { algumas técnicas }[\ldots] \text { " }\end{array}$ & $\begin{array}{l}\text { "Eu nunca tive oportunidade de ter um contacto profundo e } \\
\text { reflexivo com a grelha do ISCED." }\end{array}$ \\
\hline Estudante-D & $\begin{array}{l}\text { "[...] no meu caso, eu achei muito } \\
\text { interessante o ISCED-POSTE }[\ldots] "\end{array}$ & $\begin{array}{l}\text { "[...] tem várias sessões que ajudam o aprendiz a } \\
\text { desenvolver sua maneira de ensinar em diversos aspetos } \\
\text { específicos." }\end{array}$ & \\
\hline Estudante-R & $\begin{array}{l}\text { "[...] eu diria que o ISCED-POSTE é }[\ldots] \\
\text { mais crítico e leva o professor a refletir } \\
\text { mais na sua atividade e a }[\ldots] \text { ser mais } \\
\text { coerente" }\end{array}$ & $\begin{array}{l}\text { "[...] O ISCED-POSTE está em forma escrita, e sempre que o } \\
\text { estudante preencher descritores, deverá suportar este } \\
\text { preenchimento com documentos prováveis que podem ser } \\
\text { planos de aulas, folhas de observação, notas e outros } \\
\text { elementos vindos do professor." }\end{array}$ & $\begin{array}{l}\text { "[...] a nossa grelha de reflexão do ISCED }[\ldots] \text { ", Não havia nada }[\ldots] \\
\text { que provasse aquilo que se escrevia }[\ldots] . " \text { " "[...] aquilo não era uma } \\
\text { reflexão, preenchia-se uma folha simplesmente }[\ldots] \text { pra se cumprir } \\
\text { formalidade." }\end{array}$ \\
\hline Estudante-A1 & $\begin{array}{l}\text { "Sem sombra de dúvidas o ISCED-POSTE } \\
{[\ldots] \text { " }}\end{array}$ & $\begin{array}{l}\text { "[...] o ISCED-POSTE é muito mais completo }[\ldots] \text { ". "[...] vai } \\
\text { muito além, fala }[\ldots] \text { dos aspetos do curriculum, a } \\
\text { elaboração do curriculum, fala do próprio assessment }[\ldots] \text {, } \\
\text { que nós não tínhamos noutra grelha }[\ldots] \text { "... }\end{array}$ & $\begin{array}{l}\text { "[...] é um instrumento simples de três a quatro páginas no máximo, } \\
{[\ldots] \text {. E refletia apenas algumas competências, mínimas }[\ldots] "}\end{array}$ \\
\hline
\end{tabular}

Educ. Anál., Londrina, v.2, n.1, p.97-120, Jan./jun. 2017 


\section{Vila e Matos}

Estudante-F “[... na minha opinião gostaria de salientar que o ISCED-POSTE seria melhor $[\ldots]^{\prime \prime}$

"E... eu acho que se nós usássemos isto seria muito melhor." "[...] O ISCED-POSTE é mais inovador, com noções mais detalhadas e mais profundas também."

"É mais do que evidente, que o ISCEDPOSTE é a ferramenta mais séria e melhor de ser utilizada $[\ldots]^{\prime \prime}$
“[...] o ISCED-POSTE "dá exatamente [...] o que é que nós esperamos [...] que você faça dentro da sala da aula [...]". "[...] é uma reflexão mais crítica"

“[...] o ISCED-POSTE é algo mais organizado, mais abrangente e contempla elementos que exigem reflexão do ensino de língua inglesa."

"[...] leva o estudante a refletir de modo independente sobre o processo todo das práticas pedagógicas e não só."
“[ . ] a grelha de reflexão do ISCED limita-se em fazer uma reflexão da tua própria aula e das aulas observadas de um modo empírico [...]". "[...] a reflexão do ISCED é muito teórico, e porque também não há acompanhamento assim rigoroso [...] do que estás a fazer."

"A grelha de reflexão do ISCED parece-me um pouco limitada, [...]". "[...] o que... nós usamos no ISCED, é que simplesmente algo que é só para preencher e mais nada [...]"

"A grelha de reflexão do ISCED, não exige muito de nós, e faz com que não aprendamos quase nada com aquilo."

Fonte: Elaboração do autor. 
Da análise, constatamos que os participantes preferem o ISCED-POSTE do que a atual grelha de reflexão utilizada nas aulas práticas no ISCED-Luanda. Como observamos, as principais razões que lhes levam a optar pelo o ISCED-POSTE prendem-se em acreditarem que este portefólio encoraja a reflexão das PP; é um instrumento sério e exige a apresentação de evidências que suportem todas as declarações que os estudantes proferem nas suas reflexões. Segundo os participantes, o ISCED-POSTE contém elementos de reflexão que vão além da sala da aula, permitindo que eles reflitam não somente na aula, mas em todas as fases da prática pedagógica. Para os participantes, o ISCED-POSTE contempla uma organização lógica e coerente dos descritores que refletem competências que os estudantes necessitam para a o ensino da Lingua Inglesa; os participantes afirmaram finalmente que aquele portefólio proporciona aprendizagem criativa e autónoma.

\section{Considerações Finais}

Da questão colocada, se o ISCED-POSTE se apresentará eficaz e inovador na aprendizagem reflexiva e autónoma das práticas pedagógicas da formação inicial de professores? A pesquisa constatou que o ISCED-POSTE ajuda o estudante enquanto professor formando a organizar a sua atividade docente, promove a criatividade, a aprendizagem reflexiva e autónoma, é um instrumento inovador e recomenda-se a implementação no curso de formação inicial de professores. A pesquisa demonstrou ainda que ao utilizar o portefólio, os descritores mais preenchidos foram da categoria Resources, refletida 520 vezes. Verificou-se também que as principais evidências que sustentaram o preenchimento do ISCED-POSTE foram os planos de aulas e as grelhas de observação. Por outro lado, quase metade dos participantes não preencheu os descritores relacionados com a utilização das TICs, o que nos levou a concluir que o sistema privilegia a abordagem tradicional no ensino. A categoria Dossier mais expressiva foi a Evidence from Lesson Observation and Evaluation, congregou a metade (50\%) das evidências compiladas pelos participantes.

A pesquisa limitou-se a adaptar o ISCED-POSTE nas práticas pedagógicas, sugerimos às futuras pesquisas que envolvessem os professores e supervisores na utilização do portefólio ou introduzir o portefólio no curriculum da formação inicial de professores. Esta pesquisa pode servir de modelo para outros contextos que privilegiam as abordagens tradicionais de ensino. 


\section{Referências}

BARDIN, L. Análise de conteúdo. Lisboa: Edições 70, 2011.

CAKIR, A.; BALCIKANLI. C. The use of the EPOSTL to foster teacher autonomy: ELT student teachers' and teacher trainers' views. Australian Journal of Teacher Education, Perth, v. 32, n. 3, p. 1-16, 2012.

CARTWRIGHT, L. How consciously reflective are you? In: DEBRA, M.; LESLEY, C. (Ed.). Developing reflective practice: a guide for beginning teachers. London: Open University, 2011. p. 55-68.

GONÇALVES, T. N. R. Investigar em educação: fundamentos e dimensões da investigação qualitativa. In: MARIANA, G. A.; NAIR, R. A. (Ed.). Investigar em educação: desafios da construção de investigadores num campo multi-referenciado. Lisboa: FCT, 2010. p. $45-48$.

HOXHA, M.; TAFANI, V. European Portfolio for Student - Teachers of Languages (EPOSTL) and Insights from Student - Teachers' Feedback. Academic Journal of Interdisciplinary Studies, v. 4, n. 3, p. 71-78, 2015.

JACET. Adapting European Portfolio for Student Teachers of Languages (EPOSTL) to the Japanese Educational Context. Tokio: JACET Publisher, 2010.

JIMBO, H. et al. A Comprehensive Study on the Framework of English Language Teachers Professional Development in Japan. Tokio: JACET, 2013.

MAKINEM, K. The use of the personal statement. In DAVID, N.; ANNE-BRIT, F.; BARRY, J. (Ed.). Using the european portfolio for student teachers of languages. Strasbourg: Council of Europe, 2011. p. 45-53.

MCGREGOR. D. What can reflective practice mean for you and why should you engage in it? In: DEBRA, M.; LESLEY, C. (Ed.). Developing reflective practice: a guide for beginning teachers. London: Open University, 2011. p. 1-20.

NEWBY, D. et al. European portfolio for student teachers of languages: a reflection tool for language teacher education. Brussels: Council of Europe, 2007.

NIHLÉN, C. What goes into the EPOSTL dossier and why? In: DAVID, N.; ANNE-BRIT, F.; BARRY, J. (Ed.). Using the european portfolio for student teachers of languages.

Strasbourg: Council of Europe, 2011. p. 55-62.

RICHARDS, J. Towards reflective teaching: the teacher Trainer. A Practical Journal for those who Train, Mentor, and Educate TESOL teachers, v. 5, n. 3, p. 4-8, 1991. 